to address and to assess accurately the number of cases of active euthanasia as a proportion of all deaths in Britain. This proportion is probably less than the $1-2 \%$ reported in a Dutch survey ${ }^{4}$ undertaken just before new, more permissive legislation in 1993.

In their survey in 1988 of Australian general practitioners, Kuhse and Singer reported that almost two thirds of their sample believed that the law should be changed to allow doctors to take active steps to end life in some circumstances. ${ }^{\prime}$ Our results suggest considerable support among general practitioners and hospital consultants for changes in the law on euthanasia, although the question in our survey allowed doctors to consider only a single option-whether active euthanasia should be legal. In all, $46 \%$ of doctors were prepared to consider practising active euthanasia if it became legal. In a survey of general practitioners in Britain in $1987,35 \%$ of doctors said that they would consider practising active euthanasia if it became legal, ${ }^{5}$ compared with $40 \%$ of Australian doctors who said the same in $1988 .^{1}$

\section{RELIGIOUS BELIEFS}

No association existed between a doctor practising active euthanasia and holding a religious belief. Significant associations existed, however, between a doctor holding a religious belief and $(a)$ the belief that the law on euthanasia should not be changed $(P<0.01)$ and $(b)$ being unwilling to practise active euthanasia if it became legal $(P<0.01)$. Thus the attitudes held by some doctors with religious beliefs seem to be at variance with their behaviour, implying painful personal dilemmas. As in all other aspects of medical practice, a doctor must retain the right to act according to his or her own conscience or ideological view.

\section{CONCLUSION}

The high response rate in our survey indicates great interest in euthanasia among doctors. Our findings have implications for both professional and educational policies in Britain. Firstly, the current law on euthanasia is not satisfactory for patients. Patients may be aware that, although they may request active euthanasia, doctors cannot provide it legally; indeed, to raise this issue may be thought to compromise their relationship with the doctor. Conversely, remaining silent may also affect this relationship. A doctor may think that he or she cannot raise the issue for personal, professional, or legal reasons, and so communication between doctors and patients may be blocked. Secondly, if a patient raises the issue of active

\section{Clinical implications}

- Few data exist in Britain on the incidence of euthanasia or on doctors' attitudes towards euthanasia

- This study showed that almost half of the doctors surveyed had been asked by a patient to take active steps to hasten death

- A third of the doctors who had been asked to take active steps had complied with a patient's request

- Almost half of all doctors would consider taking active steps to hasten a patient's death if it became legal to do so

- British law on euthanasia is not satisfactory for either patients or doctors, and euthanasia should be discussed more openly

euthanasia he or she does so without knowing how the doctor is likely to respond. Not only is this unfair to patients but it may lead to those who wish to hasten their deaths seeking out doctors who will be sympathetic to their request. Thirdly, the fact that active euthanasia is illegal may deprive doctors of access to sources of adequate and effective advice and support, both professional and personal. Finally, the taboo nature of the subject and the legal and religious prohibitions prevent adequate education about euthanasia during medical training. It is important, therefore, that euthanasia should be discussed more openly and effectively.

We thank Dr R E J Dyball, Mr B C Regan, and Professor $M \mathrm{H}$ Johnson for their comments and suggestions during the preparation of the text. This survey was made possible with the aid of a grant from the Nuffield Foundation to Professor $M$ H Johnson and Dr V Navaratnam.

1 Kuhse H, Singer P. Doctors' practices and attitudes regarding voluntary euthanasia. Med f Aust 1988;148:623-7.

2 Van Der Wal G, Van Eijk JThM, Leenen HJJ, Spreeuwenberg C. Euthanasia and assisted suicide. I. How often is it practised by family doctors in the Netherlands? Fam Pract 1992;9:130-4.

3 Euthanasia. Conclusions of a BMA working party set up to review the association's guidance on euthanasia. $B M \mathcal{F}$ 1988;296:1376-7.

4 Van Der Maas PJ, Van Delden JJM, Pijnenborg L, Looman CWN. Euthanasia and other medical decisions concerning the end of life. Lancet 1991;338: $669-74$

5 National Opinion Poll Market Research. Attitudes towards euthanasia amongst Britain's general practitioners. London: NOPMR, 1987.

(Accepted 6 Fanuary 1994)
Birmingham and Midland Eye Hospital, Birmingham B3 2NS

T Potamitis, registrar

M Fouladi, senior house officer

R K Aggarwal, senior registrar

H S Jones, research associate A R Fielder, professor of ophthalmology

Correspondence to:

Mr Potamitis.

$B M \mathcal{F}$ 1994;308:1334-5

\section{General practitioners' awareness of different techniques of cataract surgery: implications for quality of care}

\author{
T Potamitis, M Fouladi, R K Aggarwal, \\ H S Jones, A R Fielder
}

With the introduction of fundholding, general practitioners can now purchase treatment from the provider of their choice. To obtain the best treatment for their patients they need to keep abreast of new developments in a large range of specialties. The past decade has seen profound changes in ophthalmology, particularly in cataract surgery. Extracapsular cataract extraction and phacoemulsification have largely superseded intracapsular cataract extraction, mainly because of the higher risk of sight threatening complications with intracapsular extraction. ${ }^{22}$ Although extracapsular surgery is now the most commonly used method in the United Kingdom, $2 \%-4 \%$ of ophthalmologists routinely perform intracapsular surgery ${ }^{34}$ and $1 \%$ do not routinely use intraocular lens implants. ${ }^{4}$ The quality of cataract treatment available therefore varies greatly between units. We examined general practitioners' familiarity with different types of cataract surgery and their ability to evaluate the clinical merits of these methods.

\section{Methods and results}

As the quality of cataract surgery varies mainly because of the difference between intracapsular and extracapsular cataract extraction, we identified ophthalmic units where both techniques were performed routinely and surveyed 593 general practitioners within the catchment areas of these units.

A total of $367(62 \%)$ completed questionnaires were received. Intracapsular extraction was the best known 
method of cataract surgery ( 309 general practitioners), followed by extracapsular extraction (301). Forty seven general practitioners were familiar with phacoemulsification, 26 were unaware of any of the methods used, and 43 were familiar with all three methods. Only 69 general practitioners expressed a preference for which method was used. The intracapsular technique was often preferred, and few of those expressing a preference chose phacoemulsification (table). When referring patients with cataracts, only 32 general practitioners said that their choice of consultant was influenced by the surgical method they used.

Methods of cataract surgery preferred by general practitioners

\begin{tabular}{lc}
\hline Preferred method & $\begin{array}{c}\text { No of } \\
\text { general practitioners } \\
(\mathrm{n}=367)\end{array}$ \\
\hline None & 298 \\
Intracapsular extraction & 29 \\
Extracapsular extraction & 27 \\
Phacoemulsification & 10 \\
Phacoemulsification or extracapsular extraction & 3 \\
\hline
\end{tabular}

\section{Comment}

As general practitioners can now choose their provider, quality of outcome assumes a greater importance. Many who responded to our questionnaire commented that they did not consider it necessary to have such detailed knowledge of specialised surgery. This would be so if all types of cataract extraction were equal, but we know this not to be true. We found that intracapsular cataract extraction was best known, not surprisingly as it has been available the longest. Although general practitioners were equally aware of extracapsular surgery, however, few expressed a preference for which method was used, which suggests insufficient knowledge to distinguish between the two. This is further reinforced by the high proportion who preferred intracapsular surgery, implying an inadequate appreciation of the advantages of modern methods.

We used cataract surgery as an example of a commonly performed specialist procedure (seventh most frequently performed operation in 1989-90)..$^{5}$ However, all specialties are undergoing change, and hopefully these changes will have distinct advantages and benefits for the patient. Furthermore, a new variable has now been introduced into the decision making process: that of cost. Hospital referral patterns are influenced by waiting times, which may well be influenced by cost. In the internal market in health care purchasers must understand the clinical advantages and disadvantages of various procedures when choosing treatment for their patients; if they do not the quality of patient care will not even enter the equation.

1 Miami Study Group. Cystoid macular edema in aphakic and pseudophakic eyes. Am f Ophthalmol 1979;88:45-8.

2 McDonnell PJ, Patel A, Green WR. Comparison of intracapsular and extracapsular cataract surgery. Ophthalmology 1985;92:1208-23.

3 Courtney P. The national cataract surgery survey. I. Method and descriptive features. Eye 1992;6:487-92.

4 Hodgkins PR, Luff AJ, Morrell AJ, Botchway LT, Fetherstone TJ, Fielder AR. Current practice of cataract extraction and anaesthesia. $\mathrm{Br} f$ Ophthalmol AR. Current pract

5 Department of Health. Hospital episode statistics. Vol 1. England financial year 1989-90. London: DoH, 1993:133.

(Accepted 3 March 1994)

\section{Accidental ingestion of methadone by children in Merseyside}

\section{J M Binchy, E M Molyneux, J Manning}

Royal Liverpool Children's Hospital, Alder Hey, Liverpool L12 2AP

$\mathrm{J} M$ Binchy, registrar in accident and emergency medicine

E M Molyneux, consultant in paediatric accident and emergency medicine

Wirral Hospital, Arrowe Park, Merseyside L49 5PE $\mathrm{J}$ Manning, consultant paediatrician

Correspondence to:

Dr Molyneux.

$B M f$ 1994;308:1335-6
The potential for accidental ingestion of methadone by children was highlighted in America in the $1970 \mathrm{~s}^{1-5}$ We studied children presenting to Merseyside hospitals after ingesting methadone to identify possible preventive measures and management.

\section{Patients, methods, and results}

We obtained information on the circumstances, timing, dose, family history, clinical details, and outcome for all children who had accidentally ingested methadone syrup in the Mersey region during November 1989 to March 1993. There were 44 episodes in 42 children; the number increased from nine in 1990, 13 in 1991, to 18 in 1992. The average age of the children was 34 (range 11-84) months; 29 were boys.

In 30 cases the type of methadone container was known: 22 were screwtop bottles, three were cups, two were open lemonade bottles, one was cotton wool in a bottle top, and only two were child resistant containers.

In 32 cases the methadone had been prescribed for a parent. In the remainder it was prescribed for the parent's partner or relative. The estimated volume ingested ranged from a lick to $200 \mathrm{ml}$.

Most ingestions were during the day; only two occurred between midnight and 9 am. The average delay between ingestion and arrival at hospital was 1 hour 35 minutes (range 15 minutes to 12 hours).

Two children died, both before arrival at hospital and after considerable delay. Of the survivors, 21 were drowsy, 10 had respiratory depression, 17 had pinpoint pupils, four were hypotensive and two had convulsions. Seventeen were asymtomatic.

Twenty children were given a bolus of naloxone, 14 of whom also had a naxolone infusion. Twenty two received ipecacuanha. Six needed no treatment. Thirty nine children were admitted, two were sent home, and one was taken home against medical advice. Twenty nine were in hospital for 24 hours, one for $24-48$ hours, and six for three or more days (three for social reasons and three for chest infections). All three with chest infections had depressed levels of consciousness and respiration.

\section{Comment}

The number of accidental methadone ingestions by children doubled from 1990 to 1992 . The Liverpool Drug Dependency Unit was established in 1989 with about 400 adults receiving methadone. In 1993 there were 800 patients, who were responsible for 500 children between them. Over half of Liverpool's family doctors prescribe methadone. In November 1992,2739 prescriptions were issue for a total of 14831 of methadone syrup in Liverpool (family health services authority, personal communication).

Methadone is a long acting opiate (half life 25 hours) and is readily absorbed orally. It is given as a sweet green liquid containing the equivalent of $1 \mathrm{mg}$ of morphine per ml. There is no legal requirement that it be dispensed in child resistant containers. Liverpool family health services authority has funded the supply of such containers, and we recommend that this be done nationally. At present methadone is attractive in colour and taste; changing to a bitter tasting liquid would stop children taking large amounts.

Three reasons may account for the delay in seeking help. Firstly, methadone users may not realise the 